\title{
الوضع الحالي والتصور المستقبلي للحالة التظذوية في مصر
}

\section{جابر أحمد بسيوني * حسين يوسف عميش* شعبان علي سالم * علي سعد أبو سالم *"}

* قسم الاقتصاد الزراعي - كلية الزراعة - سابا باثنا - جامعة الإسكندرية

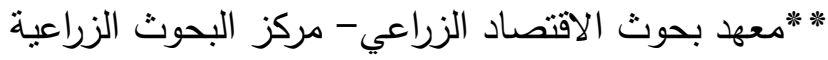

الملخص: تتعدد المواد الغذائية التي ينتاولها الإنسان ، وتختلف هذه المواد من بلد لآخر وأحيانا في الأفاليم المختلفة

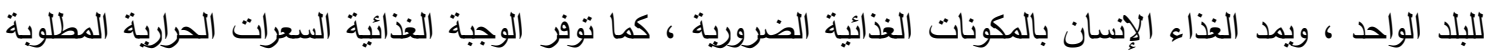

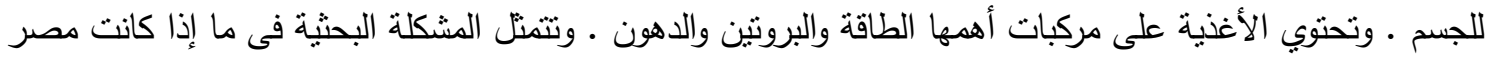

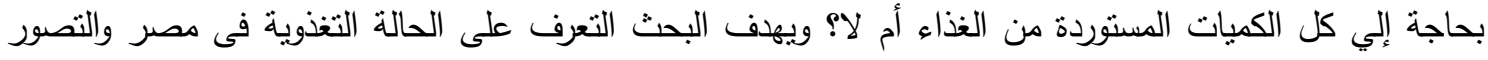

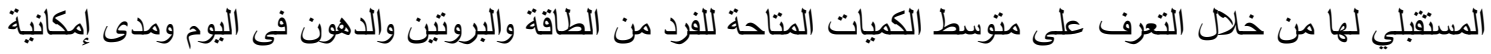

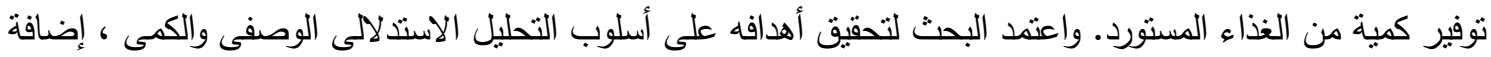

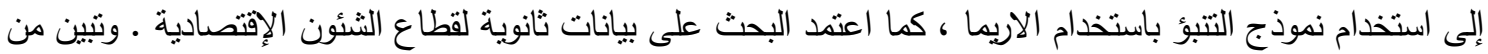
الننائج أن متوسط الكية الكلية من الطاقة المتاحة للفرد في اليوم للفتزة (2000-2016 ) تبلغ نحو

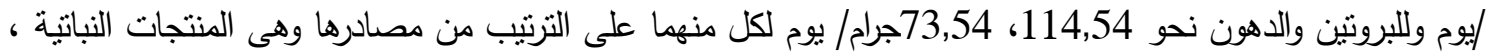

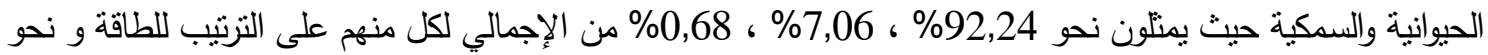

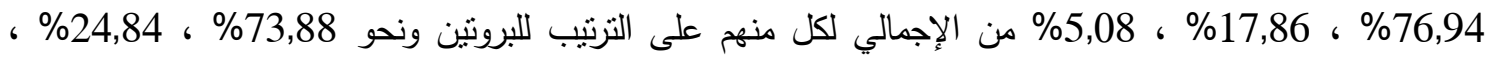

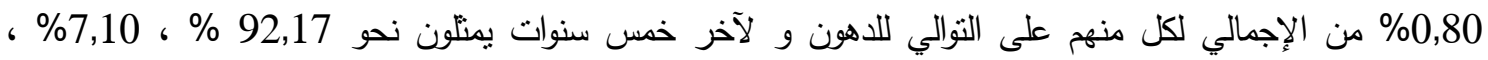

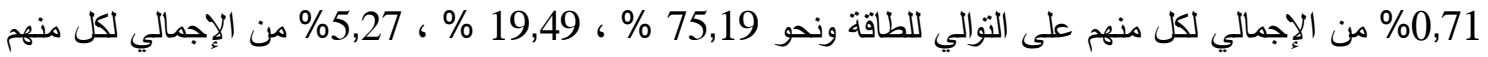
على الترتيب للبروتين ونحو 74,80\% ، 23,86 \% ، 0,80\% من الإجمالي لكل منهم على النتالي للاهون، ومنوسط

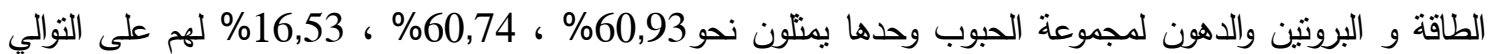

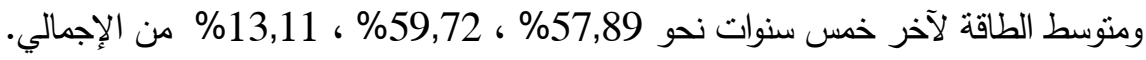

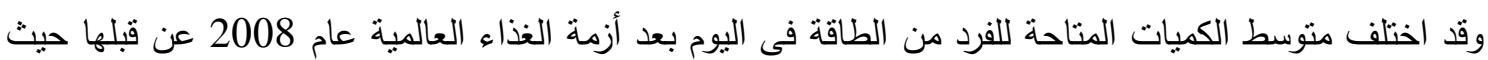

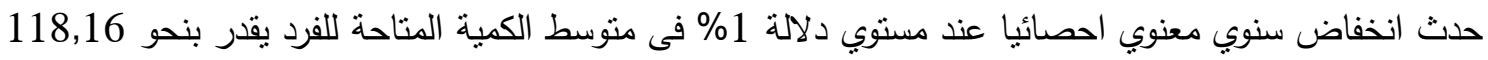
كالوري /يوم ؛ ومتوسط الكمية المتاحة للفرد من البروتين والدهون لا تختلف قبل فيل وبعد أزمة الغذاء العاء العالمية ؛ بينما

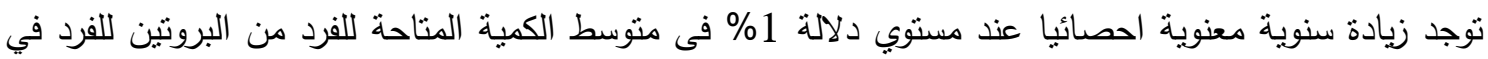
اليوم تقدر بنحو 3,22 جرام/ يوم وقد يرجع ذلك إلى تتفيذ عدد من مشروعات الثروة السمكية والتى أدث بدورها لزيادة سنوية فى منوسط المتاح للفرد في اليوم منه. واتضح من التتبؤ بالحالة التخذوية في مصر للفترة (2017-2022) باستخدام نموذج اريما واختيار أفضل نموذج

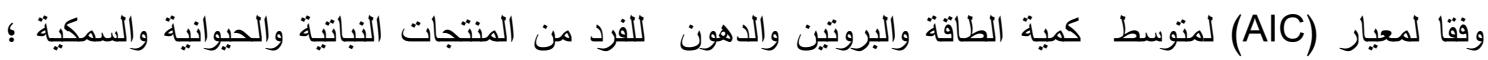
حيث من المتوقع أن يزداد متوسط كمية الطاقة بنحو 109,21\% ، 10,08\% للمنتجات النباتية والحيوانية وانخفاضها بنحو 1,54\% للمنتجات السمكية ، وتخفض لمجموعة الحبوب بنحو 1,6\% ؛ وبنلك يكون من المنوقع أن يزداد منوسط 
نصيب الفرد من الطاقة بنحو 9,19\% ؛ كما أنه من المتوقع أن يزداد متوسط كمية البروتين من المنتجات الحيوانية والسمكية بنحو 3,5\%، 2,35\% وانخفاضها بنحو 10,79\% للمنتجات النبانية ، وانخفاض متوسطها لدجموعة الحبوب بنحو 20,98 \% ؛ ومن المتوقع انخفاض متوسط نصيب الفرد من البروتين بنحو 7,28\%، كما أنه من المتوقع انخفاض كمية الدهون من المنتجات النبانية والسمكية بنحو 11,36\% \%1,57، وزيانتها بنحو 2,88\% للمنتجات الحيوانية وانخفاضها لهجموعة الحبوب بنحو 12,94\% ؛ وأن ينخفض متوسط نصيب الفرد من الدهون بنحو 8,55\%. الكلمات الكثافة : الطاقة المستهلكة ، البروتين ، الدهون ، الحالة التغذوية ، التتبؤ باريما مقدمة : تتعدد المواد الغذائية التى يتتاولها الإنسان ، وتختلف هذه المواد من بلد إلى آخر وأحياناً في الأقاليم المختلفة للبلد الواحد ، ويعرف (احمد وعبد الرؤوف ، 2002) الغذاء على أنه جميع المواد الغذائية سواء كانت من

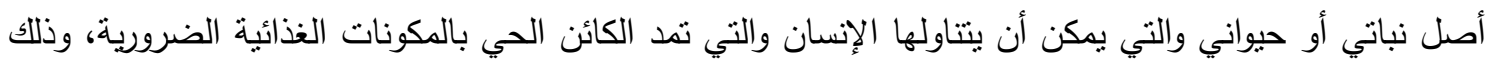

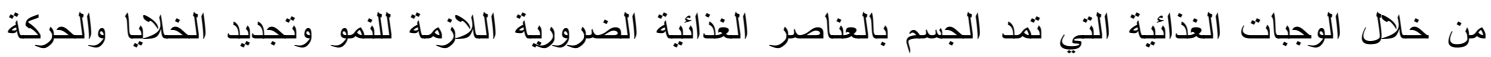

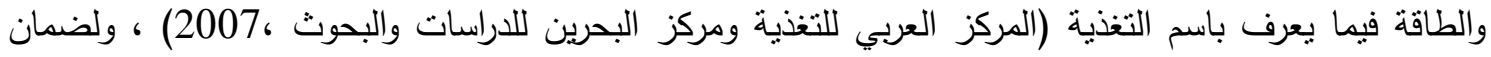
الاستقادة منها يتوجب أن تكون وجبة متكاملة وهي التي تزود الجسم بجميع العناصر الغذائية وبكميات كافية لسد

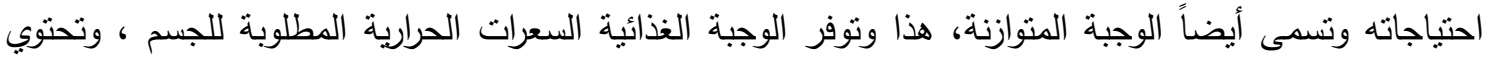
الأطعمة أو الأغذية التي تؤكل على مركبات ومواد كيميائية مختلفة، وهذه المركبات والمواد الكيميائية المختلفة

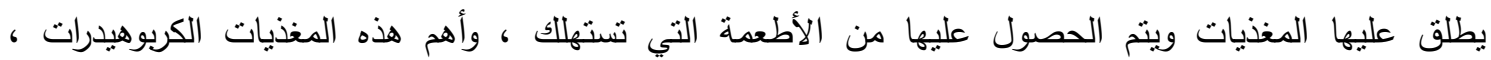
والبروتينات والدهون ؛ والتي يحتاجها الجسم لأن هذه المغذيات تزود الإنسان بالطاقة. ويتم الحصول عليها من الأغذية المختلفة وبيلغ منوسط إحتياج الفرد من الذكور فى عمر 25 إلى 50 عام نحو 2900 سعر حرارى /يوم

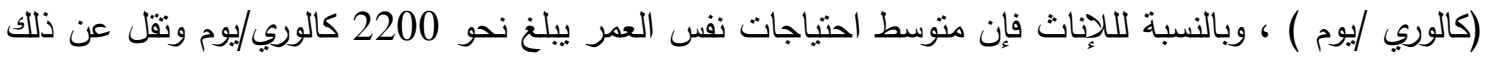
للأعمار الأكبر ، كما تختلف تلك الكميات حسب النشاط البدني الذي يقوم به الفرد والعمر (منظمة الصحة العالمية ،

.(Woerner,2015 ، 2005

\section{المشكلة البحثية}

نظراً لزيادة عدد السكان وعدم كفاية الانتاج المحلى من بعض السلع الغذائية مما أثز سلبا على الميزان التجاري الزراعي

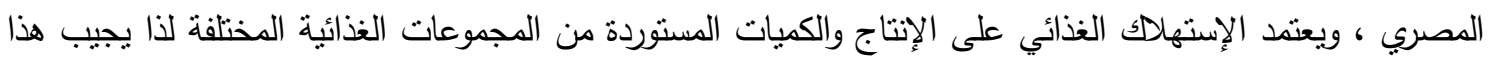

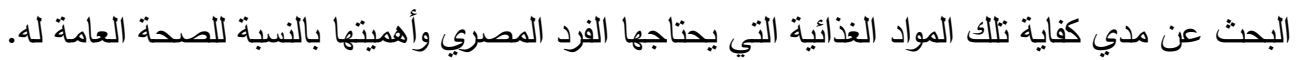

\section{الهذف من البحث}

يهذف البحث التعرف على الحالة التخذوية فى مصر والتصور المستقبلي لها من خلا التعرف على متوسط الكميات المتاحة للفرد من الطاقة والبروتين والدهون فى اليوم ومدى إمكانية توفيرها من الغذاء المستورد. الأسلوب البحثي ومصادر البيانات

يعتمد البحث على أسلوب التحليل الاستدلالى الوصفى والكمى من خلال استخدام المتغيرات الصورية لقياس أثز أزمة الغذاء العالمية على منوسط نصيب الفرد من الكميات المتاحة من الطاقة والبروتين والدهون، إضافة إلى استخدام نموذج التتبؤ باستخدام الاريما ؛ كما اعتد البحث على بيانات ثانوية منشورة وغير منشورة من هيئات حكومية منل وزارة الزراعة وقطاع الثئؤن الإقتصادية والجهاز المركزى للتعبئة العامة والإحصاء والأبحاث والدراسات المتعلقة بموضوع البحث. 
النتائج البحثية وإلمناقشة

أولاً- تطور إجمالى كمية الطاقة المتاحة للفرد في اليوم:

يتضح من بيانات جدول رقم (1) الذي يتناول إجمالي كمية الطاقة المتاحة للفرد في اليوم من مصادرها المختلفة من

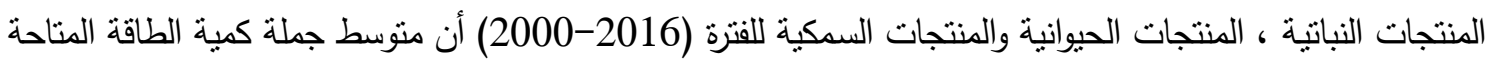
بنالك الفترة للفرد في اليوم من الننتجات الغذائية السابقة تبلغ نحو 4060,65 كالورى بانحراف معياري بلغ نحو

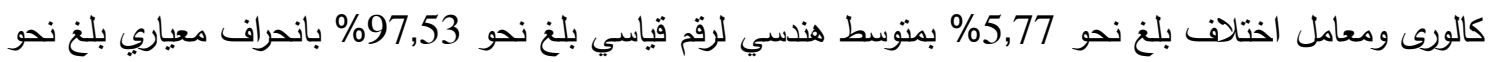

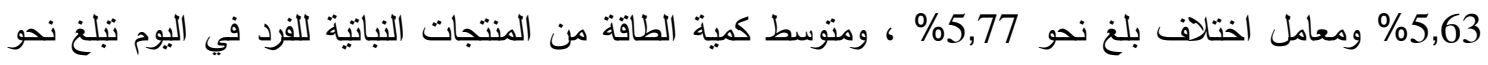

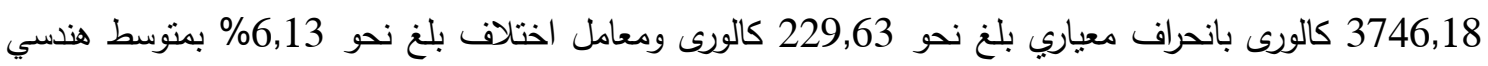

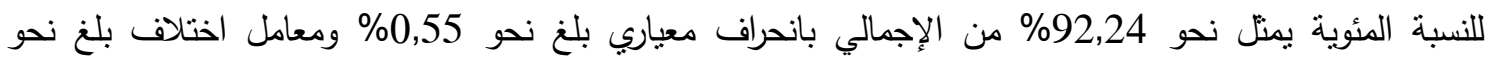

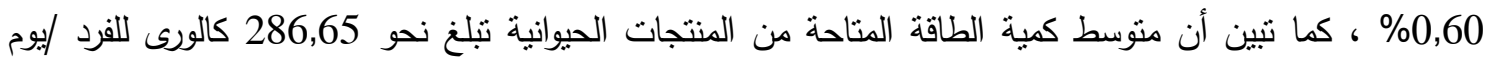

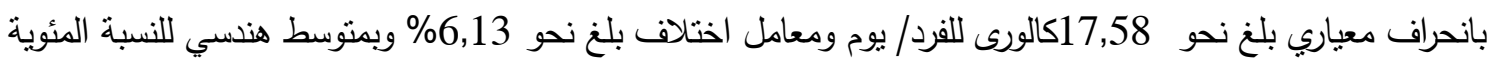

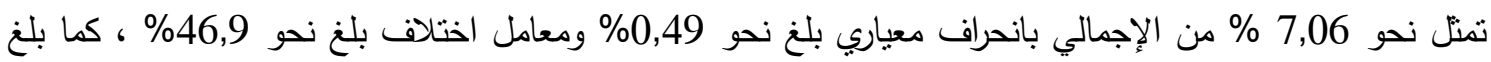
متوسط كمية الطاقة المتاحة من المنتجات السمكية نحو 27,82 كالورى للفرد /ليوم بانحراف معياري بلغ نحو

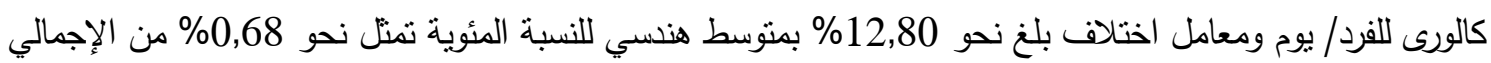
بانحراف معياري بلغ نحو 0,10\% ، ومعامل اختلاف بلغ نحو 14,71\% , ومتوسط كمية الطاقة المتاحة من مجموعة الحبوب تبلغ نحو 2478,29 كالورى للفرد //يوم بانحراف معياري بلغ نحو 199,07 كالورى للفرد/ يوم ومعامل اختلاف

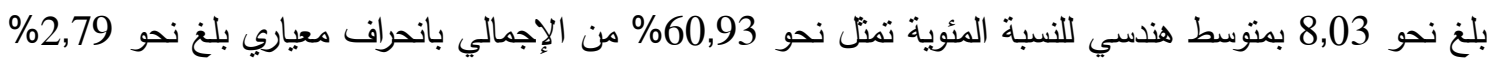

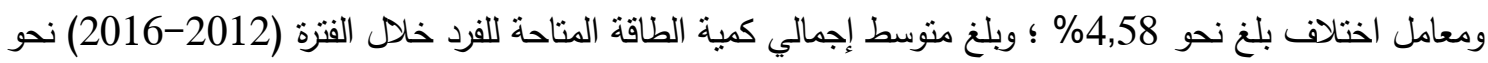
3846,80 كالورى تمنل نحو 92,40\% كمنوسط هندسي لنفس الفنزة وتنثل المنتجات النباتية والحيوانية والسمكية نحو 3546,60 ، 272,80 ، 27,40 كالورى لكل منهم على التزتيب ويمنل كل منهم كمتوسط هنسي للنسبة المئوية نحو

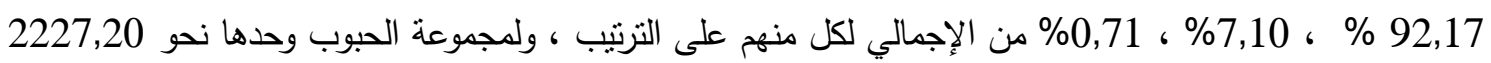
كالوري تمثل كنسبة مئوية نحو 57,89\% ، من الإجمالي .

ثانياً - تطور إجمالي كمية البروتين المتاحة للقرد في اليوم:

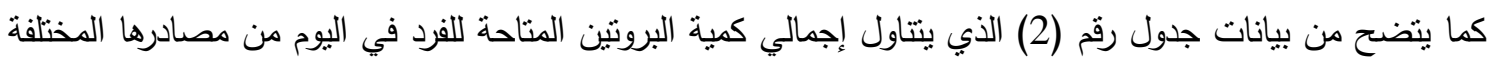

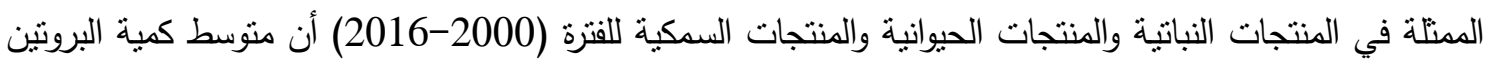

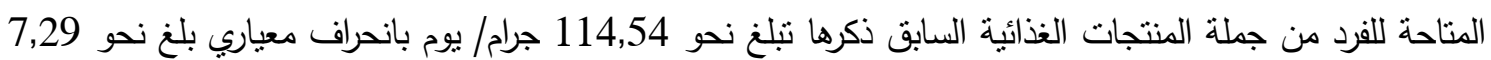

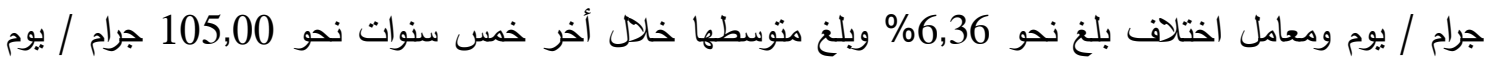

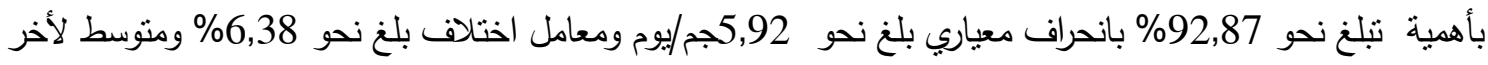

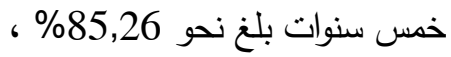


جدول رقم (1). كمية الطاقة المتاحة للفرد في اليوم للفترة (2000-2016)

\begin{tabular}{|c|c|c|c|c|c|c|c|c|c|c|}
\hline \multicolumn{2}{|c|}{ الحبوب } & \multicolumn{2}{|c|}{ المنتجات السـمكية } & \multicolumn{2}{|c|}{ المنتجات الحيوانية } & \multicolumn{2}{|c|}{ المنتجات النباتيـة } & \multicolumn{2}{|c|}{ الجملة العموميـة } & \multirow[b]{2}{*}{ البيان } \\
\hline من الإجمالي & الكمية & من الإجمالي & الكمية & من الإجمالي & الكمية & من الإجمالي & الكمية & القياسيم\% & الكمية & \\
\hline 65.5 & 2704 & 0.75 & 31 & 6.54 & 272 & 92.71 & 3854 & 100 & 4157 & 2000 \\
\hline 63.56 & 2482 & 0.95 & 37 & 7.20 & 281 & 91.86 & 3587 & 93.94 & 3905 & 2001 \\
\hline 65.48 & 2593 & 0.76 & 30 & 7.58 & 300 & 91.67 & 3630 & 95.26 & 3960 & 2002 \\
\hline 65.02 & 2598 & 0.75 & 30 & 8.33 & 333 & 90.92 & 3633 & 96.13 & 3996 & 2003 \\
\hline 62.45 & 2618 & 0.67 & 28 & 6.85 & 287 & 92.49 & 3877 & 100.48 & 4192 & 2004 \\
\hline 60.25 & 2665 & 0.70 & 31 & 7.05 & 312 & 92.25 & 4080 & 106.4 & 4423 & 2005 \\
\hline 60.69 & 2694 & 0.56 & 25 & 6.62 & 294 & 92.81 & 4120 & 106.78 & 4439 & 2006 \\
\hline 61.61 & 2542 & 0.61 & 25 & 7.32 & 302 & 92.07 & 3799 & 99.25 & 4126 & 2007 \\
\hline 61.36 & 2649 & 0.53 & 23 & 6.69 & 289 & 92.77 & 4005 & 103.85 & 4317 & 2008 \\
\hline 61.88 & 2599 & 0.55 & 23 & 6.6 & 277 & 92.86 & 3900 & 101.03 & 4200 & 2009 \\
\hline 61.58 & 2467 & 0.67 & 27 & 7.06 & 283 & 92.26 & 3696 & 96.37 & 4006 & 2010 \\
\hline 58.49 & 2384 & 0.64 & 26 & 6.84 & 279 & 92.52 & 3771 & 98.05 & 4076 & 2011 \\
\hline 57.94 & 2285 & 0.68 & 27 & 6.85 & 270 & 92.47 & 3647 & 94.88 & 3944 & 2012 \\
\hline 58.22 & 2405 & 0.61 & 25 & 6.68 & 276 & 92.71 & 3830 & 99.37 & 4131 & 2013 \\
\hline 58.15 & 2286 & 0.79 & 31 & 7.05 & 277 & 92.16 & 3623 & 94.56 & 3731 & 2014 \\
\hline 59.38 & 2102 & 0.73 & 26 & 7.97 & 282 & 91.30 & 3232 & 85.16 & 3540 & 2015 \\
\hline 55.80 & 2058 & 0.76 & 28 & 7.02 & 259 & 92.22 & 3401 & 88.72 & 3688 & 2016 \\
\hline $60.93^{*}$ & 2478.29 & $0.68^{*}$ & 27.82 & $7.06^{*}$ & 286.65 & *92.24 & 3746.18 & $97.53^{*}$ & 4060.65 & المتوسط \\
\hline $57.89^{*}$ & 2227.2 & $0.71^{*}$ & 27.4 & $7.01^{*}$ & 272.8 & *92.17 & 3546.6 & $92.4^{*}$ & 3846.80 & المنوسط (2012-2016) \\
\hline 2.79 & 199.07 & 0.10 & 3.56 & 0.49 & 17.58 & 0.55 & 229.63 & 5.63 & 234.18 & الانحر أف المعياري \\
\hline 4.58 & 8.03 & 17.71 & 12.80 & 6.94 & 6.13 & 0.60 & 6.13 & 5.77 & 5.77 & معامل الاختلاف\% \\
\hline
\end{tabular}

المصدر:جمعت وحسبت من وزارة الزراعة ، قطاع الثئون الاقتصادية ،الميزان الغذائي، للفترة (2000-2016). 
جدول رقم (2) كمية البروتين المتاحة للفرد في اليوم للفترة (2000-2016)

\begin{tabular}{|c|c|c|c|c|c|c|c|c|c|c|c|}
\hline $\begin{array}{l}\text { \% من الإجمالي } \\
\text { \% }\end{array}$ & القباسي & بروتين & $\begin{array}{l}\text { \% من الإجمالي } \\
\text { \% }\end{array}$ & السنتجات المنية & 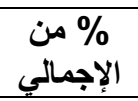 & المنتجات المية & 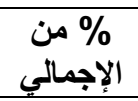 & التبنتباتة & القياستي & بروتين & البيان \\
\hline 63.12 & 100.00 & 77.70 & 5.44 & 6.70 & 15.68 & 19.30 & 78.88 & 97.10 & 100.00 & 123.10 & 2000 \\
\hline 61.16 & 90.99 & 70.70 & 6.40 & 7.40 & 14.88 & 17.20 & 78.72 & 91.00 & 93.91 & 115.60 & 2001 \\
\hline 61.10 & 97.04 & 75.40 & 5.19 & 6.40 & 18.15 & 22.40 & 76.66 & 94.60 & 100.24 & 123.40 & 2002 \\
\hline 59.72 & 92.54 & 71.90 & 5.56 & 6.70 & 19.60 & 23.60 & 74.83 & 90.10 & 97.81 & 120.40 & 2003 \\
\hline 61.82 & 94.21 & 73.20 & 5.32 & 6.30 & 17.57 & 20.80 & 77.11 & 91.30 & 96.18 & 118.40 & 2004 \\
\hline 61.31 & 96.65 & 75.10 & 5.31 & 6.50 & 17.88 & 21.90 & 76.82 & 94.10 & 99.51 & 122.50 & 2005 \\
\hline 63.70 & 98.71 & 76.70 & 4.32 & 5.20 & 16.86 & 20.30 & 78.82 & 94.90 & 97.81 & 120.40 & 2006 \\
\hline 59.66 & 90.22 & 70.10 & 4.43 & 5.20 & 18.13 & 21.30 & 77.45 & 91.00 & 95.45 & 117.50 & 2007 \\
\hline 60.84 & 93.56 & 72.70 & 4.10 & 4.90 & 16.40 & 19.60 & 79.50 & 95.00 & 97.08 & 119.50 & 2008 \\
\hline 61.37 & 92.02 & 71.50 & 4.21 & 4.90 & 16.31 & 19.00 & 79.48 & 92.60 & 94.64 & 116.50 & 2009 \\
\hline 60.09 & 88.16 & 68.50 & 5.18 & 5.90 & 17.54 & 20.00 & 77.28 & 88.10 & 92.61 & 114.00 & 2010 \\
\hline 60.23 & 85.97 & 66.80 & 5.05 & 5.60 & 18.12 & 20.10 & 76.83 & 85.20 & 90.09 & 110.90 & 2011 \\
\hline 60.27 & 81.21 & 63.10 & 5.16 & 5.40 & 18.53 & 19.40 & 76.31 & 79.90 & 85.05 & 104.70 & 2012 \\
\hline 61.17 & 86.36 & 67.10 & 4.65 & 5.10 & 18.69 & 20.50 & 76.66 & 84.10 & 89.11 & 109.70 & 2013 \\
\hline 59.79 & 82.11 & 63.80 & 5.81 & 6.20 & 19.49 & 20.80 & 74.70 & 79.70 & 86.68 & 106.70 & 2014 \\
\hline 58.63 & 77.35 & 60.10 & 5.17 & 5.30 & 21.46 & 22.00 & 73.37 & 75.20 & 83.27 & 102.50 & 2015 \\
\hline 58.78 & 76.71 & 59.60 & 5.62 & 5.70 & 19.43 & 19.70 & 74.95 & 76.00 & 82.37 & 101.40 & 2016 \\
\hline${ }^{*} 60.74$ & *89.36 & 69.43 & *5.08 & 5.85 & *17.86 & 20.46 & *76.94 & 88.23 & *92.87 & 114.54 & المتوسط \\
\hline *59.72 & *80.67 & 62.68 & *5.27 & 5.54 & *19.49 & 20.48 & *75.19 & 78.98 & *85.26 & 105.00 & اللتوسط (2016-2012) \\
\hline 1.35 & 7.15 & 5.56 & 0.61 & 0.74 & 1.62 & 1.50 & 1.78 & 6.98 & 5.92 & 7.29 & الانحر أف المعياري \\
\hline 2.22 & 8.00 & 8.00 & 12.04 & 12.61 & 9.05 & 7.32 & 2.31 & 7.91 & 6.38 & 6.36 & معامل الاختلاف\% \\
\hline
\end{tabular}

المصدر :جمعت وحسبت من وزارة الزراعة ، قطاع الثئون الاقتصادية ،الميزان الغذائي، للفترة (2000-2016). 
كما تنين أن منوسط كمية البروتين المتاحة للفرد من المنتجات النباتية بلغت نحو 88,23هرام/يوم بانحراف معياري بلغ نحو 6,98 جرام/ يوم ومعامل اختلاف بلغ نحو 7,91\% وتمنل نحو 76,94\% من الإجمالي بانحراف معياري بلغ نحو 1,78جم/ يوم ومعامل اختلاف بلغ نحو 02,31\% وبلغ متوسطها خلال أخر خمس سنوات نحو 78,98 جرام/ يوم تمتل نحو 75,19\% من الإجمالي ،كما تيين أن متوسط كية البروتين المتاحة للفرد من المنتجات الحيوانية بلغت نحو

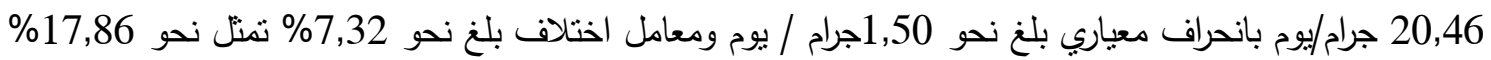

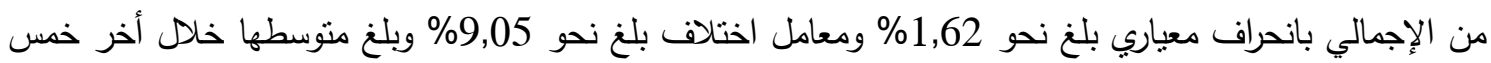
سنوات نحو 20,48 جرام / يوم تمنل نحو 19,49\% من الإجمالي ، في حين بلغ منوسط كمية البروتين المتاحة للفرد

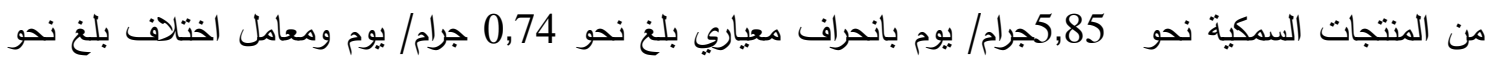

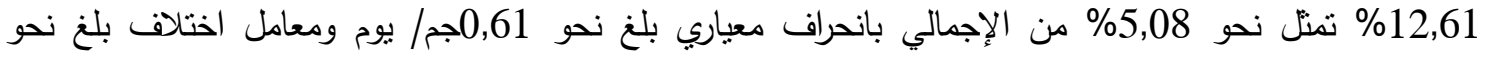

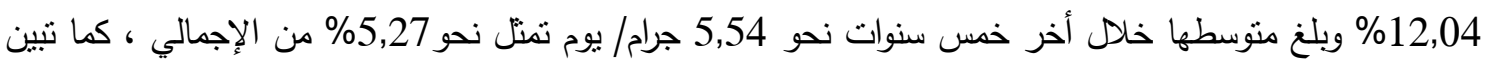
أن متوسط كمية البروتين المتاحة للفرد من مجموعة الحبوب بلغت نحو 96,43جرام/ يوم بانحراف معياري بلغ نحو 5,56 جرام/ يوم ومعامل اختلاف بلغ 8\% تمثل نحو 89,36\% من الإجمالي بانحراف معياري بلغ نحو

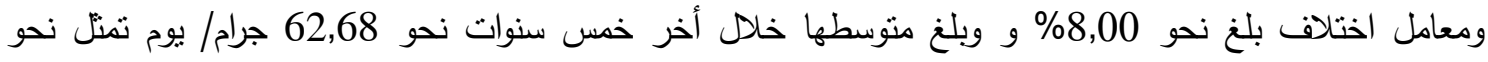
\% 80,67 من الإجمالي.

ثالثاً - تطور إجمالي كمية الدهون المتاحة للفرد في اليوم: يتضح من بيانات جدول رقم (3) الذي ينتاول إجمالي كمية الدهون للفرد في اليوم من إجمالي مصادرها المختلفة المنتلة في المنتجات النبانية والمنتجات الحيوانية والمنتجات السمكية للفترة (2000-2016) أن متوسط إجمالي كمية الدهون المتاحة للفرد من جملة المنتجات الغذائية السابق ذكرها بلغت نحو 73,54جرام/ يوم بانحراف معياري بلغ نحو

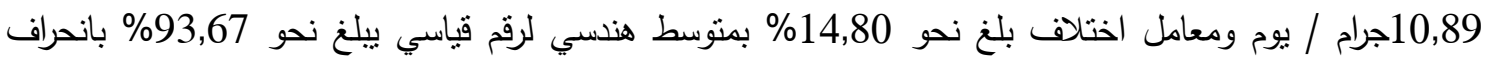
معياري بلغ نحو 14,01 \% ومعامل اختلاف بلغ نحو 14,96\% وبلغ منوسطها خلال أخر خمس سنوات نحو جرام/ يوم تنتل نحو 96,50\% من الإجمالي ، كما تنين أن منوسط كمية الدهون المتاحة للفرد من المنتجات النباتية

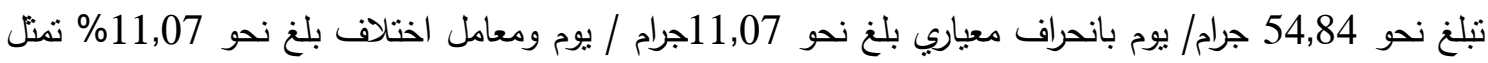

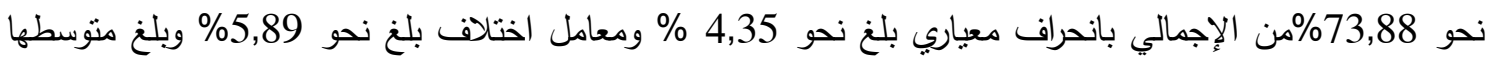
خلال أخر خمس سنوات نحو 57,36 جرام/يوم تمثل نحو 74,80\% من الإجمالي ،كما نتين أن منوسط كمية الدهون

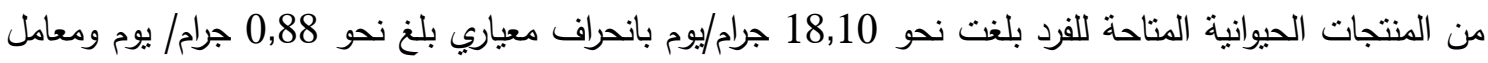

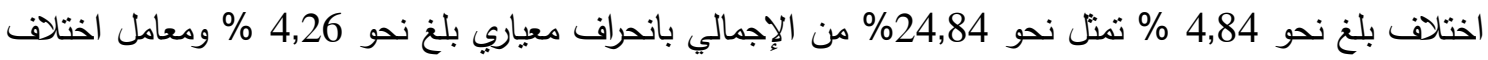
بلغ نحو 17,13\% وبلغ منوسطها خلال أخر خمس سنوات نحو 17,90جرام/ يوم تمنل نحو 23,86\% من الإجمالي. 
جدول رقم (3) كمية الدهون المتاحة للفرد في اليوم للفترة (2000-2016)

\begin{tabular}{|c|c|c|c|c|c|c|c|c|c|c|}
\hline \multicolumn{2}{|c|}{ الحبوب } & \multicolumn{2}{|c|}{ المنتجات السـمكية } & \multicolumn{2}{|c|}{ المنتجات الحيوانية } & \multicolumn{2}{|c|}{ المنتجات النباتيـة } & \multicolumn{2}{|c|}{ الجملة العموميـة } & \multirow[b]{2}{*}{ البيان } \\
\hline $\begin{array}{l}\text { \% من الإجمالى } \\
\text { \% }\end{array}$ & الكمية & \% من الإجمالى & الكمية & الإجمالى من & الكمية & الإجمالى من & الكمية & القياسمى & الكمية & \\
\hline 21.36 & 16.60 & 0.77 & 0.60 & 21.88 & 17.00 & 77.35 & 60.10 & 100.00 & 77.70 & 2000 \\
\hline 22.84 & 15.90 & 1.58 & 1.10 & 25.57 & 17.80 & 72.84 & 50.70 & 89.58 & 69.60 & 2001 \\
\hline 26.05 & 16.80 & 0.93 & 0.60 & 28.84 & 18.60 & 70.23 & 45.30 & 83.01 & 64.50 & 2002 \\
\hline 20.85 & 12.80 & 0.65 & 0.40 & 33.55 & 20.60 & 65.80 & 40.40 & 79.02 & 61.40 & 2003 \\
\hline 16.37 & 12.80 & 0.51 & 0.40 & 23.15 & 18.10 & 76.34 & 59.70 & 100.64 & 78.20 & 2004 \\
\hline 14.84 & 13.10 & 0.79 & 0.70 & 21.63 & 19.10 & 77.58 & 68.50 & 113.64 & 88.30 & 2005 \\
\hline 14.27 & 13.30 & 0.64 & 0.60 & 19.53 & 18.20 & 79.83 & 74.40 & 119.95 & 93.20 & 2006 \\
\hline 17.01 & 11.70 & 0.87 & 0.60 & 27.03 & 18.60 & 72.09 & 49.60 & 88.55 & 68.80 & 2007 \\
\hline 17.73 & 11.70 & 0.91 & 0.60 & 27.42 & 18.10 & 71.67 & 47.30 & 84.94 & 66.00 & 2008 \\
\hline 18.20 & 11.50 & 0.79 & 0.50 & 27.37 & 17.30 & 71.84 & 45.40 & 81.34 & 63.20 & 2009 \\
\hline 19.01 & 11.50 & 0.99 & 0.60 & 29.09 & 17.60 & 69.92 & 42.30 & 77.86 & 60.50 & 2010 \\
\hline 13.84 & 11.00 & 0.63 & 0.50 & 21.64 & 17.20 & 77.74 & 61.80 & 102.32 & 79.50 & 2011 \\
\hline 13.39 & 10.20 & 0.79 & 0.60 & 23.49 & 17.90 & 75.72 & 57.70 & 98.07 & 76.20 & 2012 \\
\hline 12.62 & 10.90 & 0.58 & 0.50 & 21.06 & 18.20 & 78.36 & 67.70 & 111.20 & 86.40 & 2013 \\
\hline 12.95 & 10.10 & 0.90 & 0.70 & 23.46 & 18.30 & 75.64 & 59.00 & 100.39 & 78.00 & 2014 \\
\hline 16.97 & 9.40 & 1.08 & 0.60 & 32.85 & 18.20 & 66.06 & 36.60 & 71.30 & 55.40 & 2015 \\
\hline 10.44 & 8.70 & 0.72 & 0.60 & 20.29 & 16.90 & 78.99 & 65.80 & 107.21 & 83.30 & 2016 \\
\hline *16.53 & 12.24 & ${ }^{\star} 0.80$ & 0.60 & *24.84 & 18.10 & *73.88 & 54.84 & *93.67 & 73.54 & المتوسط \\
\hline *13.11 & 9.86 & ${ }^{*} 0.80$ & 0.60 & *23.86 & 17.90 & *74.80 & 57.36 & $\star 96.50$ & 75.86 & المتوسط(2012-2016) \\
\hline 4.11 & 2.37 & 0.25 & 0.15 & 4.26 & 0.88 & 4.35 & 11.07 & 14.01 & 10.89 & الانحر اف المعياري \\
\hline 24.85 & 19.39 & 30.62 & 25.69 & 17.13 & 4.84 & 5.89 & 20.18 & 14.96 & 14.80 & معامل الاختلاف\% \\
\hline
\end{tabular}

المصدر : جمعت وحسبت من وزارة الزر اعة قطاع الثئون الاقتصادية ، الميزان الغذائي ، أعداد مختلفة للفترة (2000-2016). 
في حين بلغ متوسط كمية الدهون المتاحة للفرد من المنتجات السمكية نحو 0,60جرام/ يوم بانحراف معياري بلغ نحو 0,15 جرام/ يوم ومعامل اختلاف بلغ نحو 25,69 \% و تمثل نحو 0,80\% من الإجمالي بانحراف معياري بلغ نحو 0,25 \% ومعامل اختلاف بلغ نحو 30,62\% وبلغ منوسطها لآخر خمس سنوات نحو 0,60 جرام/ يوم تمنل نحو 0,80 من الإجمالي كما بلغ منوسط كمية الدهون المتاحة للفرد من مجموعة الحبوب نحو 12,24جرام للفرد /يوم

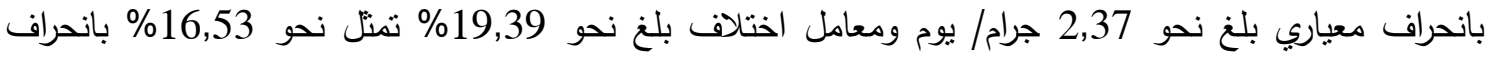
معياري بلغ نحو 4,11 \% ومعامل اختلاف بلغ نحو 24,85\% وبلغ منوسطها خلال آخر خمس سنوات نحو جرام/يوم تمثل نحو 13,11\% من الإجمالي.

رابعاً-أثر أزمة الغذاء العالمية على متوسط كمية الغذاء المتاحة للفرد: تعد أزمة الغذاء العالمية التي حدثت عام 2008 من أهم الأحداث التى أثرت على كميات الغذاء المتاحة للفرد ؛ ولبيان أثز أزمة الغذاء على متوسط كمية الغذاء المتاحة للفرد من الطاقة والبرونين والدهون من المنتجات النباتية والحيوانية

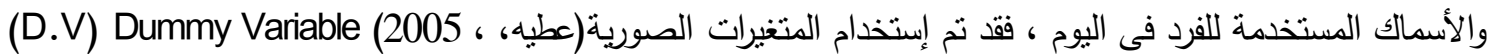

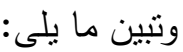
i.أثر أزمة الغذاء على متوسط كمية الطاقة الغذائية المتاحة للفرد في مصر: يتضح من المعادلة رقم (1) بجدول رقم (4) ثبوت المعنوية الإحصائية للنموذج عند مسنوى المعنوية 0,01 ، حيث بلغت قيمة (F) نحو 7.96 ، وهى لهى أكبر من قيمتها الجدولية عند نفس مستوى المعنوية ، ومن تلك المعادلة يمكن اشتقاق المعادلتان الأتيتان:.

$$
\begin{aligned}
& \text { Y1 = 2958.845+162.957T } \\
& \text { بعد أزمة الغذاء : }
\end{aligned}
$$

حيث اتضح من المعادلة المقدرة ارتفاع في المقدار الثابت لمتوسط كمية الطاقة المتاحة للفرد في اليوم بعد أزمة الغذاء عن قبلها بمقدار ارتفاع في الجزء الثابت بلغ نحو 985,89 كالوري ، لييلغ نحو

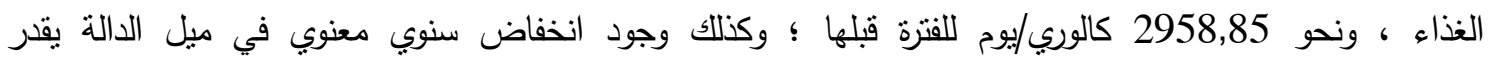
بنحو 118,16 كالوري حيث مقدار الزيادة السنوية في كمية الطاقة قبل أزمة الغذاء نحو 44,8 كالوري بعد أزمة الغذاء. 1) أثر أزمة الغذاء على متوسط كمبة الطاقة الغذائبة النباتبة المتاحة للفرد في مصر :يتضح من المعادلة رقم

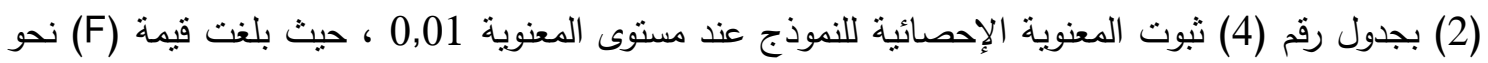
6,85 ، وهى أكبر من قيمتها الجدولية عند نفس مستوى المعنوية ، ومن تلك المعادلة يمكن اشتقاق المعادلتان

$$
\begin{gathered}
\text { الأتيتان: } \\
Y_{2}=2627.38+161.21 T_{2} \\
Y_{2}=3612.868+44.45 T_{2}
\end{gathered}
$$

حيث اتضح من المعادلة المقدرة ارتفاع في المقدار الثابت للالة بعد أزمة الغذاء عن قبلها بنحو

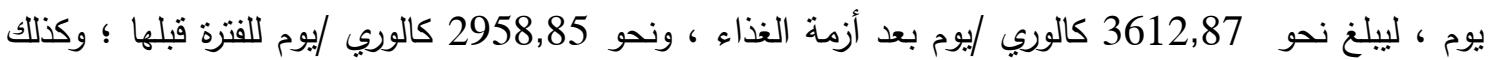
وجود انخفاض سنوي معنوي في ميل الدالة يقدر بنحو 116,76 كالوري حيث مقدار الزيادة السنوية فى كمية الطاقة قبل أزمة الغذاء نحو 161,21 كالوري مقارنة بنحو 
2) أثر أزمة الغذاء على متوسط كمية الطاقة الغذائية من مصدر حيواني المتاحة للفرد في مصر: يتضح من المعادلة رقم (3) بجدول رقم(4) ثبوت المعنوية الإحصائية للنموذج عند مسنوى المعنوية 0,05 ، حيث بلغت قيمة نحو 3,42 ، وهى أكبر من قيمتها الجدولية عند نفس مستوى المعنوية ، ومن تللك المعادلة يمكن اشتقاق

$$
\begin{aligned}
& \mathrm{Y}_{3}=280.57 \\
& \text { قبل أزمة الغذاء: } \\
& \mathrm{Y}_{3}=280.57 \\
& \text { بعد أزمة الغذاء : }
\end{aligned}
$$

حيث اتضح من المعادله المقدره عدم وجود فرق معنوى لأثز منوسط كمية الطاقة المتاحة للفرد من المصدر الحيوانى للفترة قبل أزمة الغذاء العالمية مقارنة بالفترة التالية لها عند مستويات المعنوية المألوفة. 3) أثثر أزمة الغذاء على متوسط كمبة الطاقة الغذائبة السمكبة المتاحة للفرد في مصر : يتضح من المعادلة رقم (4) بجدول رقم (4) ثبوت المعنوية الإحصائية للنموذج عند مستوى المعنوية 0,01 ، حيث بلغت قيمة (F) نحو مكانية 8,03 ، وهى أكبر من قيمتها الجدولية عند نفس مستوى المعنوية ، ومن تلك المعادلة يمكن اثتقاق المعادلتان

$$
\begin{aligned}
& \text { ق } \\
& \text { بعد أزمة الغذاء: } \quad \text { بع }
\end{aligned}
$$

حيث اتضح من المعادلة المقدرة انخفاض في المقدار الثابت للدالة بعد أزمة الغذاء العالمية عن قبلها بنحو 15,59 كالوري /يوم ، ليبلغ نحو 35,31 كالوري /يوم بعد أزمة الغذاء ، ونحو 50,90 كالوري /يوم للفترة قبلها ؛ وكذلك بهاه

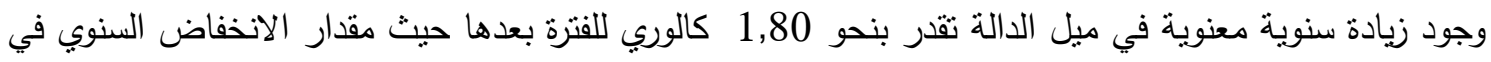
كمية الطاقة قبل أزمة الغذاء بلغت نحو 3, 3,08 كالوري مقارنة بنحو 1,28 كالوري بعدها.

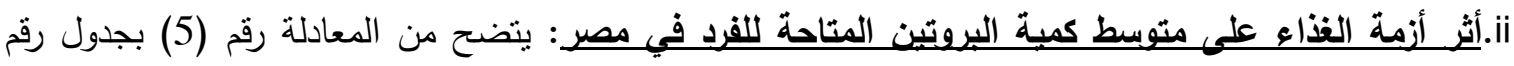

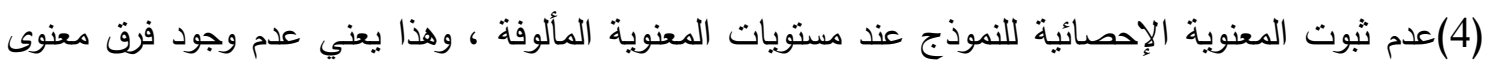

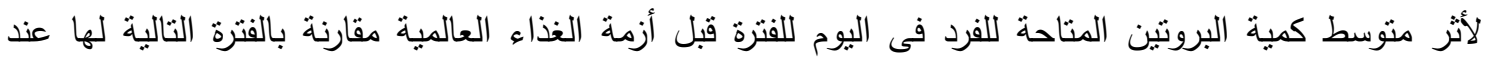

1) أثر أزمة الغذاع على متوسط كمية البروتين المتاحة للفرد من المصادر النباتية للفرد في مصر : بتضح من

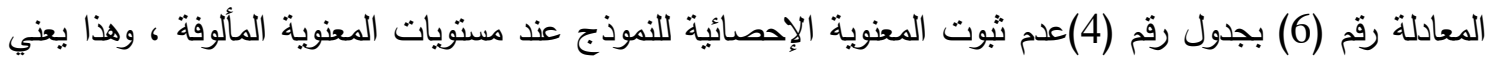

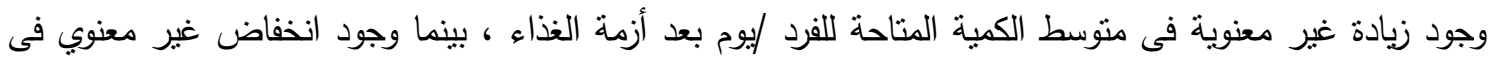

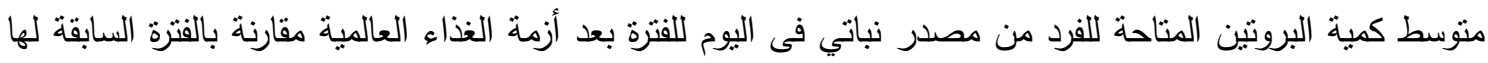
عند مستويات المعنوية المألوفة. 2) أثثر أزمة الغذاء على متوسط كمبة البروتين المتاحة للفرد من المصادر الحيوانبة للفرد في مصر : يتضح من المعادلة رقم (7) بجدول رقم (4)عدم ثبوت المعنوية الإحصائية للنموذج عند مستويات المعنوية المألوفة ، وهذا يعني وجود انخفاض فى منوسط الكمية المتاحة للفرد /يوم ، وكذلك منوسط الانخفاض السنوى فيه غيرمعنوى لأثر متوسط كمية البروتين المتاحة للفرد من مصدر حيواني فى اليوم للفترة بعد أزمة الغذاء العالمية مقارنة بالفترة 
3) أثر أزمة الغذاء على متوسط كمية البروتين السمي المتاحة للفرد في مصر: يتضح من المعادلة رقم (8) بجدول رقم (4) ثبوت المعنوية الإحصائية للنموذج عند مستوى المعنوية 1,01 ، حيث بلغت قيمة (F) نحو 11,20 ، وهى أكبر من قيمتها الجدولية عند نفس مستوى المعنوية ، ومن تلك المعادلة بمكن اشتقاق المعادلتان التاليتان:.

$$
\begin{aligned}
& \mathrm{Y}_{8}=101.687-5.955 \mathrm{~T}_{8} \\
& \text { قبل أزمة الغذاء: } \\
& \mathrm{Y}_{8}=75.112-2.734 \mathrm{~T}_{8} \\
& \text { بعد أزمة الغذاء : }
\end{aligned}
$$

حيث اتضح من المعادلة المقدرة انخفاض في المقدار الثابت للدالة بعد أزمة الغذاء العالمية عن قبلها بنحو

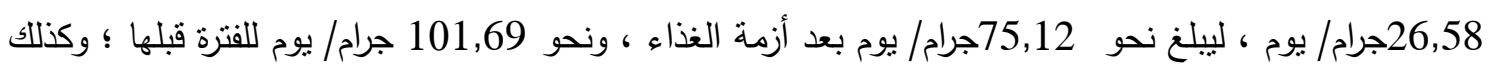

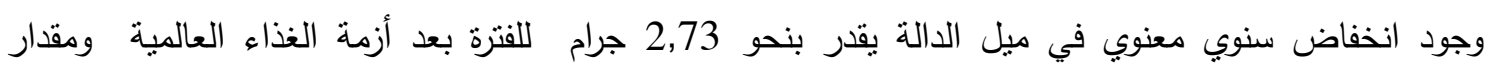

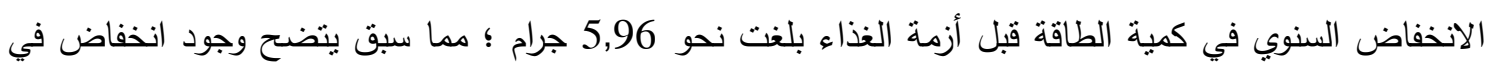

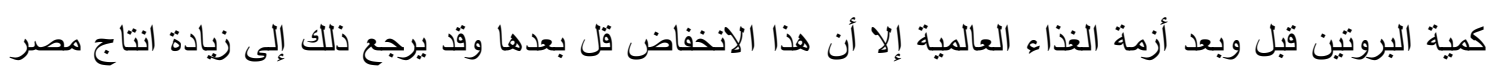
من الأسماك نتيجة التوسع في زراعته . iii.أثر أزمة الغذاء على متوسط كمبة الاهون المتاحة للقرد في مصر: يتضح من المعادلة رقم (9) بجدول رقم

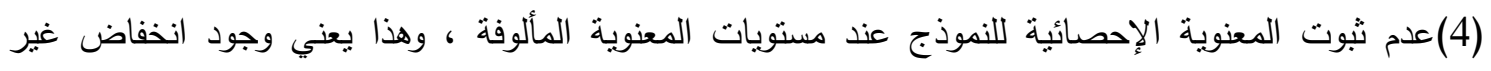

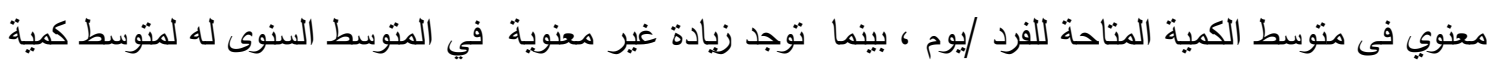

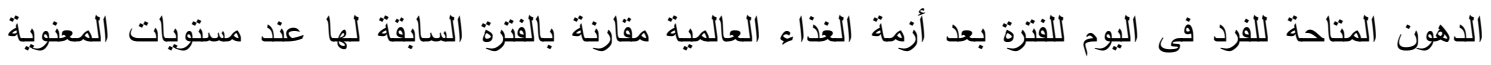
المألوفة.

1) أثر أزمة الغذاء على متوسط كمبة الدهون المتاحة للفرد من مصدر نباتي للفرد في مصر: يتضح من

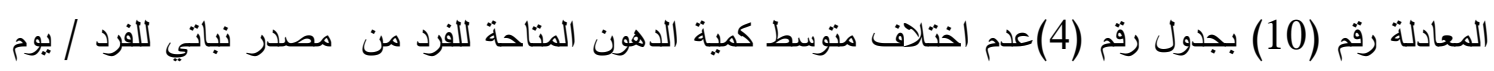

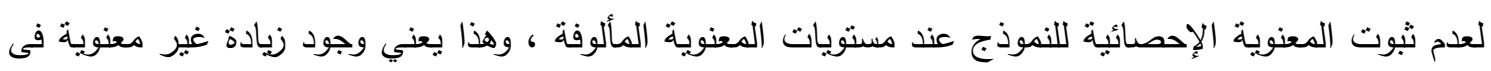

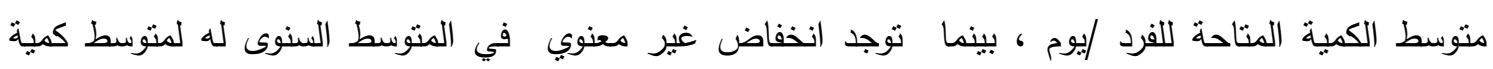
الدهون المتاحة من مصدر نباتى للفرد فى اليوم للفترة بعد أزمة الغذاء العالمية مقارنة بالفترة السابقة لها.

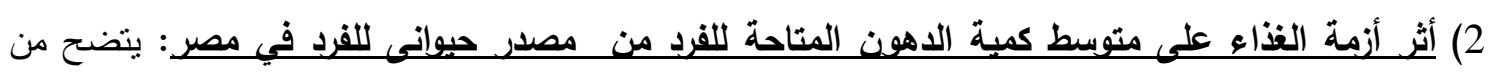

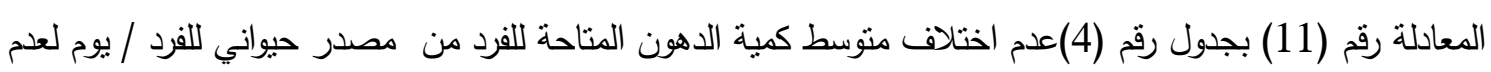

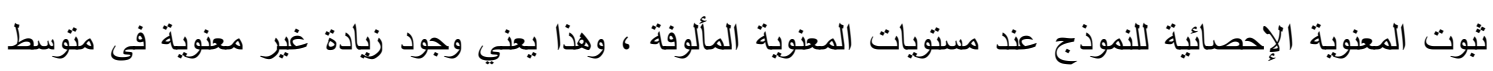

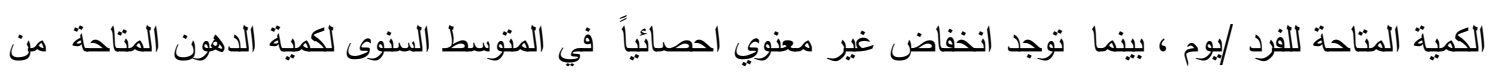

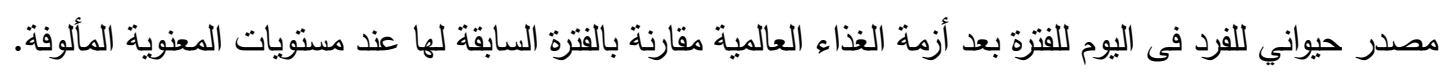

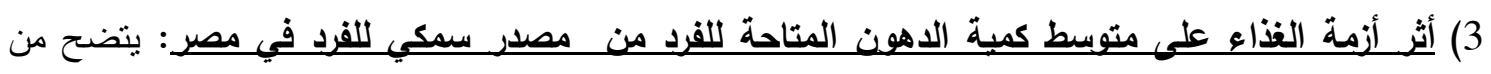
المعادلة رقم (12) بجدول رقم (4)عدم اختلاف منوسط كمية الدهون المتاحة للفرد من مصدر سمكي للفرد / يوم لعدم

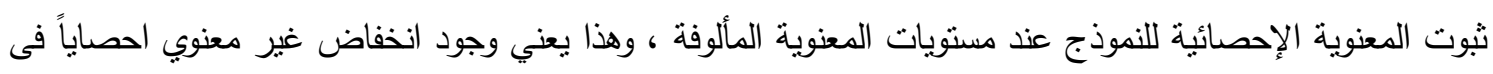
متوسط الكمية المتاحة للفرد /يوم ، بينما توجد زيادة غير معنوية احصاياً في المتوسط السنوى لكمية الدهون المناحة

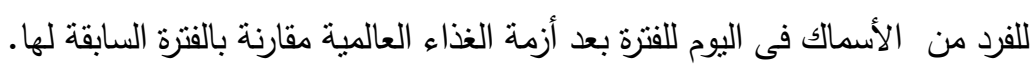


جدول رقم (4).أثر أزمة الذذاء على متوسط كمية الطاقة والبروتين والدهون المستخدمة للفرد فى اليوم

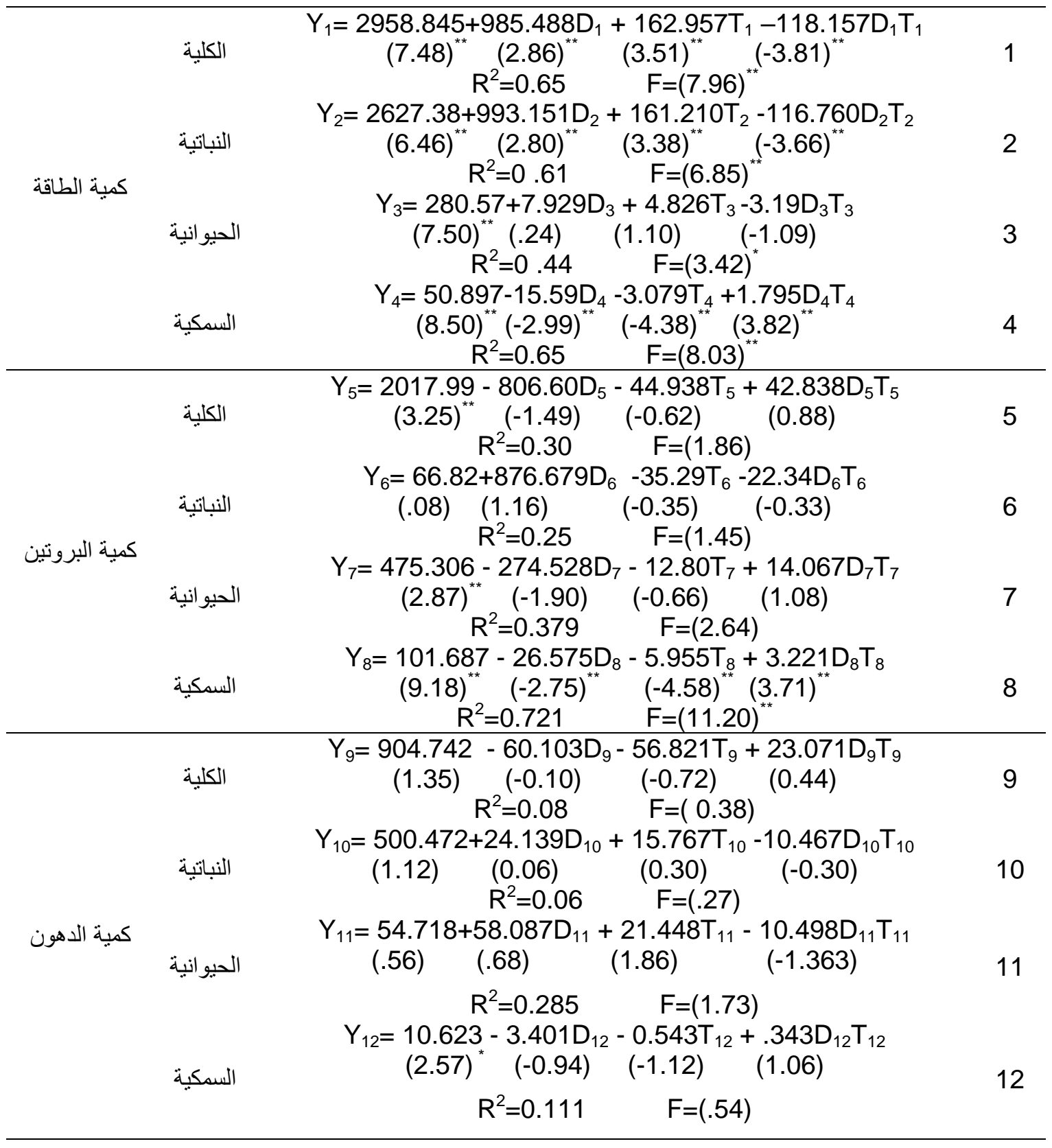

= $\mathrm{Y}_{1}, \mathrm{Y}_{2}, \mathrm{Y}_{3}, \ldots, \mathrm{Y}_{12}$

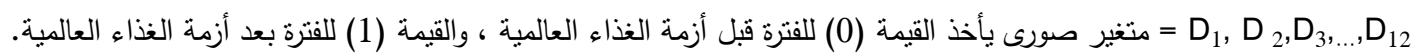
مقار التغير فى ميل الدالة. المصدر: حسبت من جداول (1) ، (2) ، (3) بالبحث.

خامسا - الوضع المستقبلي للحالة التغذوية فى مصر حتى عام 2022: توضح بيانات جدول رقم (5) التنبؤ بالحالة التغذوية في مصر للفترة (2017-2022) أي للست سنوات ونم التنبؤ باستخدام نموذج الأريما (Box- Jenkins,1976) واختيار أفضل نموذج وفقا لمعيار (AIC) كما هو موضح 
بالجدول الذي يتتاول متوسط كمية الطاقة والبروتين والدهون للفرد / يوم من المنتجات النباتية والحيوانية والسمكية ؛ حيث من المتوقع أن يبلغ متوسط كمية الطاقة الكلية للفرد نحو 4027 كالوري/ يوم عام2022 مقارئة مقارنة بنحو 3688كالوري/ يوم عام 2016 أي بزيادة عن نفس العام تقدر بنحو 9,19\% ، ومن المتوقع أن يبلغ متوسط كمية

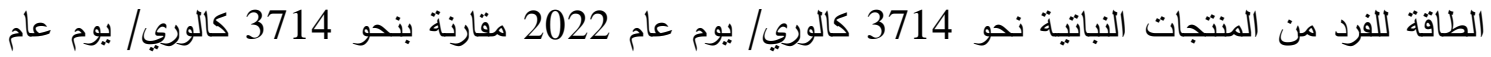
2016 أي بزيادة عن نفس العام تقدر بنحو 9,21\% ، كما أنه من المتوقع أن تبلغ متوسط كمية الطاقة من المنتجات الحيوانية للفرد نحو 285,1 كالوري/يوم عام 2022 مقارنة بنحو 259 كالوري/ يوم عام 2016 أي بزيادة عن نفس العام تقدر بنحو 10,08\% ، وكذلك من المتوقع أن يبلغ متوسط كمية الطاقة من المنتجات

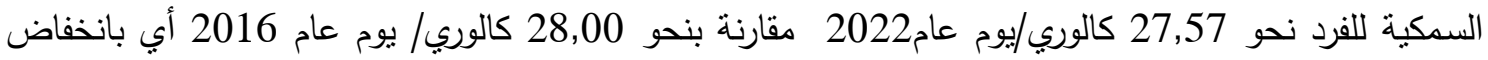
عن نفس العام يقدر بنحو 1,54\% ، وتعد مجموعة الحبوب في مصر من أهم المصادر للطاقة الغذائية للفرد

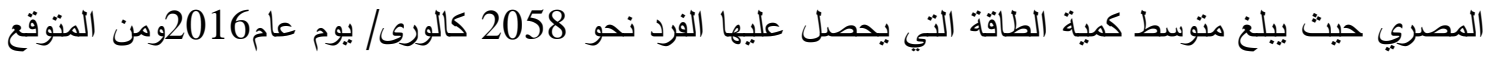

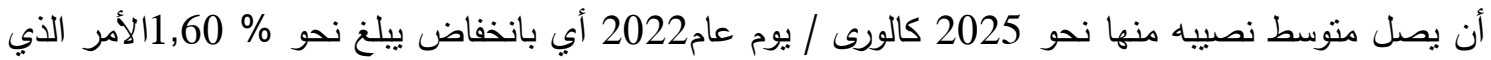
يشير إلي أن الفرد المصري سوف يحصل علي احتياجاته من الطاقة من مصادر أخري بجانب الحبوب. ومن المنوقع أن تبلغ منوسط كمية البروتين الكلية للفرد نحو 94,02 جرام/ يوم عام 2022 مقارنة بنحو

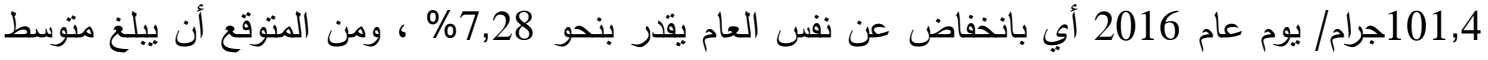
كمية البروتين للفرد من المنتجات النباتية نحو 67,8 جرام/ يوم عام أي بانخفاض عن نفس العام يقدر بنحو 10,79\% ، كما أنه من المتوقع أن تبلغ متوسط كمية البروتين من المنتجات الحيوانية للفرد نحو 20,39جرام/يوم عام 2022 مقارنة بنحو 19,7 جرام/ يوم عام 2016 أي بزيادة عن نفس العام تقدر بنحو 3,5\% ، وكذللك من المتوقع أن تبلغ متوسط كمية البروتين من المنتجات السمكية للفرد نحو 5,83 جرام/يوم عام2022 مقارنة بنحو 5,70 جرام/ يوم عام 2016 أي بزيادة عن نفس العام تقدر بنحو

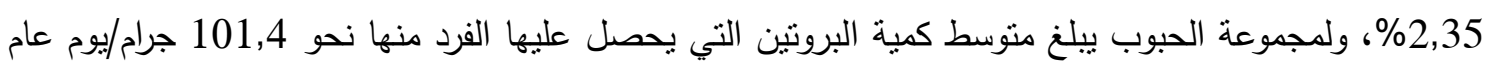

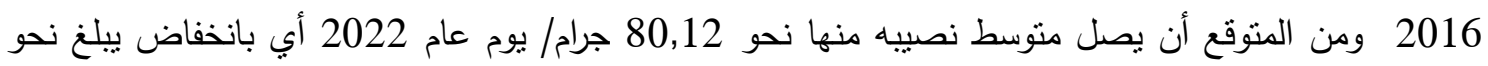
$20,98 \%$,

كما نبين من نتائج جدول (5) أنه من المتوقع أن تبلغ منوسط كمية الدهون الكلية للفرد نحو 76,18 جرام/ يوم عام2022 مقارنة بنحو 83,3 جرام/ يوم عام 2016 أي بانخفاض عن نفس العام يقدر بند بندو

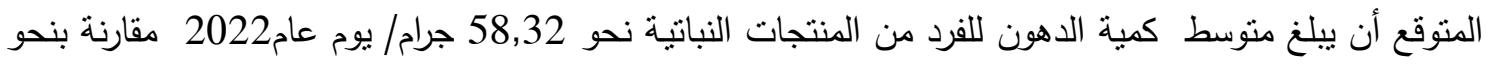

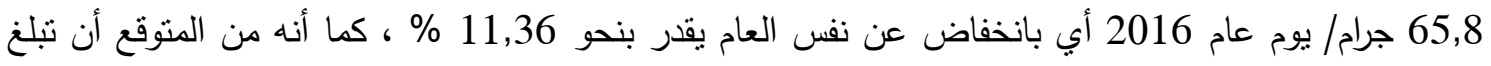

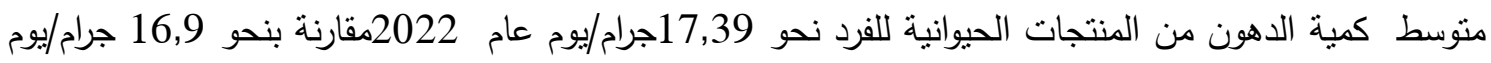
عام 2016 أي بزيادة عن نفس العام تقدر بنحو 2,88\% ، وكذللك من المتوقع أن تبلغ منوسط كمية الدهون من المنتجات السمكية للفرد نحو 0,47 جرام/يوم عام 2022 مقارنة بنحو عن نفس العام تقدر بنحو 21,57\% ، ولمجموعة الحبوب يبلغ متوسط كمية الدهون التي يحصل عليها الفرد منها

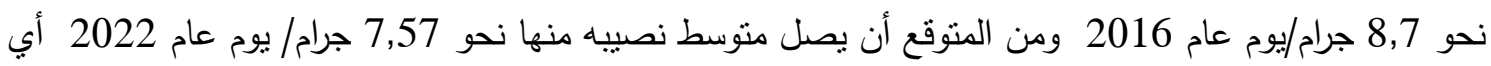
بانخفاض يبلغ نحو 12,94\% 
جدول رقم (5). التنبؤ بالحالة التظذوية للطاقة والبرتين والدهون في مصر للفترة (2017-2022)

\begin{tabular}{|c|c|c|c|c|c|c|c|c|c|c|c|}
\hline التغيرة\% & 2022 & 2021 & 2020 & 2019 & 2018 & 2017 & 2016 & AIC & النموذج المستخدم & & البيان \\
\hline 9.19 & 4027 & 4016 & 3999 & 3970 & 3923 & 3836 & 3688 & & اجمالي & & \\
\hline 9.21 & 3714 & 3705 & 3688 & 3660 & 3613 & 3534 & 3401 & 13.61 & Plant $(1,0,0,0)$ & نباتى & a< \\
\hline 10.08 & 285.1 & 285 & 284.6 & 283.7 & 281.3 & 275.1 & 259 & 8.73 & Animal $(1,0,0,0)$ & حيو اني & \\
\hline-1.54 & 27.57 & 26.96 & 26.82 & 25.74 & 28.25 & 26.54 & 28 & -1.46 & $\operatorname{LOG}(\mathrm{FISH})(3,1,0,1)^{*}$ & سمكي & 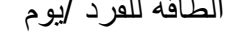 \\
\hline-1.6 & 2025 & 2057 & 2090 & 2122 & 2155 & 2187 & 2058 & & (OLS) & حبوبَ & \\
\hline-7.28 & 94.02 & 95.26 & 96.5 & 97.47 & 99.23 & 99.95 & 101.4 & & إجمالي & & \\
\hline-10.79 & 67.8 & 69.06 & 70.35 & 71.57 & 72.97 & 73.92 & 76 & 5.6 & $\mathrm{D}(\operatorname{PLANT})(1,0,0,0)^{*}$ & نباتى & \\
\hline 3.5 & 20.39 & 20.4 & 20.4 & 20.41 & 20.41 & 20.42 & 19.7 & & (OLS) & حيو اني & 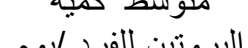 \\
\hline 2.35 & 5.83 & 5.8 & 5.75 & 5.5 & 5.85 & 5.62 & 5.7 & -1.44 & LOG(FISH) $(1,0,0,1)^{*}$ & سمكي & \\
\hline-20.98 & 80.12 & 83.64 & 85.65 & 89.74 & 92.32 & 95.26 & 101.4 & -3.73 & D2LOG(CERIAL) $(0,2,1,0)^{*}$ & حبوبّ & \\
\hline-8.55 & 76.18 & 74.67 & 64.45 & 79.78 & 69.74 & 69.68 & 83.3 & & إجمالي & & \\
\hline-11.36 & 58.32 & 56.67 & 46.26 & 61.61 & 51.6 & 51.58 & 65.8 & 7.41 & PLANT $(2,2,1,0)$ & نباتى & \\
\hline 2.88 & 17.39 & 17.44 & 17.49 & 17.54 & 17.59 & 17.64 & 16.9 & & (OLS) & حيو اني & ملوسط حيه \\
\hline-21.57 & 0.47 & 0.57 & 0.7 & 0.64 & 0.54 & 0.46 & 0.6 & -1.2 & $\operatorname{FISH}(2,1,0,1)$ & سمكي & الدهون للقرد /يوم \\
\hline-12.94 & 7.57 & 7.97 & 7.65 & 8.14 & 8.62 & 9.19 & 8.7 & -1.9 & D2LOG(CERIAL $(1,1,1,0)^{*}$ & حبوبَ & \\
\hline
\end{tabular}

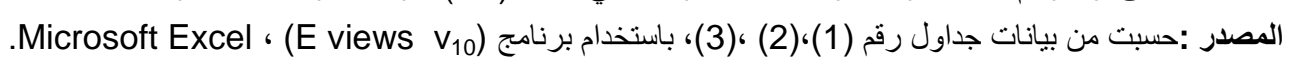




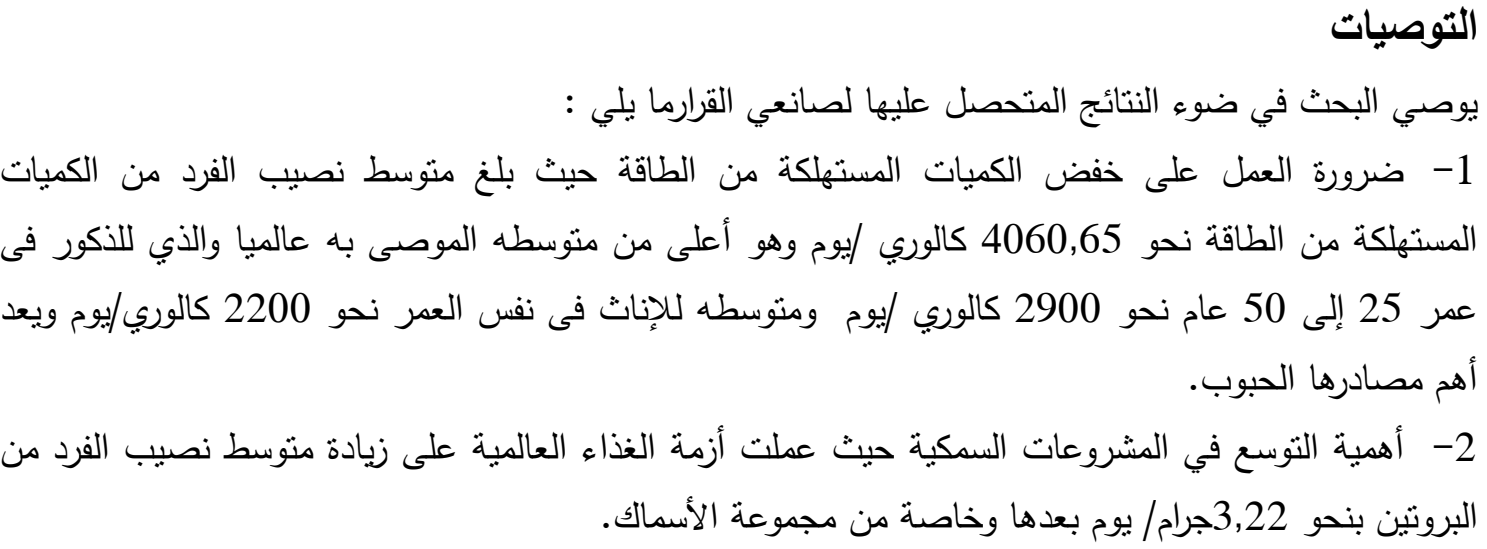

احمد ، سمير محمد وحسن عبد الرؤوف ( 2002) ـ تغذية الانسان ، بستان المعرفة للطبع والنشر والتوزيع

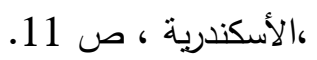
المركز العربي للتغذية ومركز البحرين للاراسات والبحوث (2007). النشاط البدني والسمنة والتغذية ، دار القلم

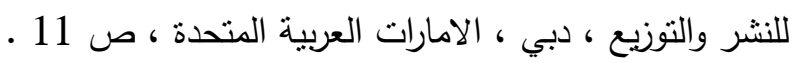
منظمة الصحة العالمية ،الكتاب الطبي الجامعي(2005) ـ الغذاء والتغذية ،اكاديميا انترناثشيونال للنشر ، بيروت ، لبنان ، ص ص 20-21 ،ص 208 . 208 . وزارة الزراعة ، قطاع الثئئن الاقتصادية ،الميزان الغذائي، أعداد مختلفة للفترة (2000-2016).

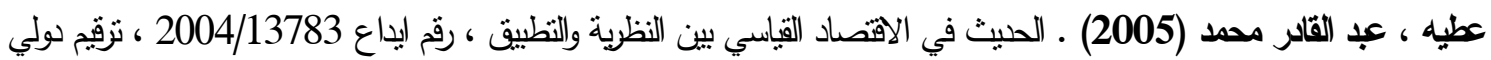

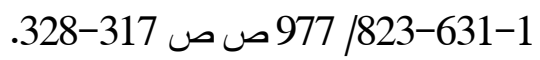

Woerner, Amanda (2015). "This Is How Many Calories You're Burning in an Hour", Daialy burn.16,11.

Box, G.E.P. and Jenkins, G.M.(1976). Time Series Analysis, Forecasting and Control. Holden-Day, San Francisco.

\title{
Summary \\ Current and prediction situation of nutritional status in Egypt
}

\author{
Bassuni ${ }^{1}$, G. A., Amish ${ }^{1}$,H. y., Salem ${ }^{2}$ Sh. A.,Abosalem ${ }^{2}$ A. S. \\ ${ }^{1}$ Dept.of Agri.Eco.,Fac.of Agri.(Saba Basha),Alex Uni. \\ ${ }^{2}$ Agri. Eco. Res. Inst- ARC, Cairo
}

ABSTRACT: There are many foods that are eaten by humans, and these substances vary from country to country and sometimes in different regions of the same country, and provides food human essential nutrients necessary as the meal provides the calories required for the body, and contains foods and compounds, including carbohydrates, proteins and fats, Whether Egypt needs all imported food; The research aims to identify the nutritional status in Egypt and its future perception by identifying the average quantities of energy, protein 
and fat available per CAPITA per day and the possibility of providing a quantity of imported food. The research also relied on descriptive and quantitative analysis method, The research was also based on secondary data for the economic affairs sector. The total average amount of energy available per person per day for the period (2016-2000) is about 4060.65 cal / day, and for protein and fat about 114.54 and $73.54 \mathrm{~g} /$ day respectively of their sources: plant products, animal and fish, accounting for about $92.24 \% 7.06 \%, 0.68 \%$ of the total respectively of energy and about $76.94 \%, 17.86 \%, 5.08 \%$ of the total, respectively of the protein And about $73.88 \%, 24.84 \%, 0.80 \%$ of the total respectively for fat and the last five years accounted for $92.17 \%, 7.10 \%, 0.71 \%$ of of the total respectively for energy and about $75.19 \%, 19.49 \%, 5.27 \%$ of The total protein, fat, protein, and fat respectively accounted for $60.93 \%, 60.74 \%$, $16.53 \%$, respectively and the average energy for the last five years was $57.89 \%$ , $59.72 \%, 13.11 \%$ of the total. The average per capita available energy per capita per day differed after the 2008 global food crisis. There was a statistically significant annual decrease at a mean level of $1 \%$ in the average available quantity per capita of $118.16 \mathrm{kcal} /$ day; the average available amount of protein and fat is not different Before and after the global food crisis; while there is a statistically significant annual increase at the level of $1 \%$ in the average quantity per capita of protein per day estimated at $3.22 \mathrm{~g} /$ day. This may be due to the implementation of a number of fisheries projects, which in turn led to an annual increase in the average Available per person per day from him. The prediction of the nutritional status of Egypt for the period (2017-2022) using the ARIMA model and the selection of the best model according to the AIC standard for average energy, protein and fat per capita of plant, animal and fishery products is expected to increase by an average of $9.21 \%$, The average per capita energy consumption is expected to increase by $9.19 \%$. the average amount of protein from animal and fish products is expected to increase by about $3.5 \% 2.35 \%$ and decreased by about $10.79 \%$ Gat plant, and lower average for a group of grain by about $20.98 \%$; The average per capita protein is expected to decline by $7.28 \%$. The amount of fat from vegetable and fish products is expected to decrease by $11.36 \%$ and $21.57 \%$ and by $2.88 \%$ for animal products, by $12.94 \%$. The individual fat is about $8.55 \%$.

The Research recommends to decision-makers that:

1.The need to work on reducing the quantities consumed energy, where the average per capita consumption of energy consumed about $4060.65 \mathrm{cal} /$ day, which is higher than the average recommended globally and the most important sources are the group of grains.

2.The importance of expansion in fisheries projects where the global food crisis has increased the average per capita protein at $3.22 \mathrm{~g} /$ day after, especially from the fish group.

Key words: total calories, protein, fat, nutritional status, predicting by using ARIMA 
مجلة الجديد في البحوث الزر اعية (كلية الزر اعة ـ سابا باشا) 